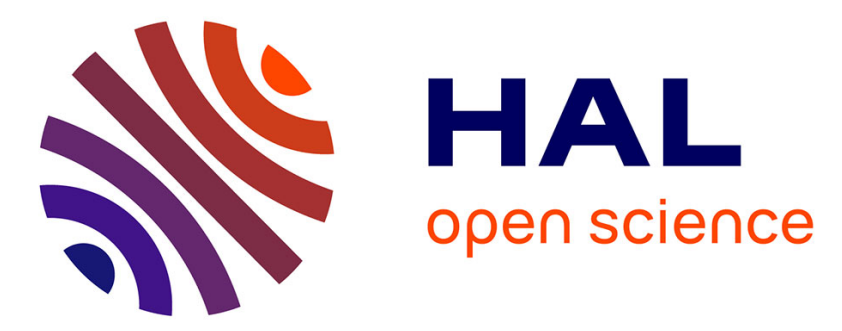

\title{
The Study of Microplasticity Mechanism in Ti-50 wt.\% Nb Alloy with High Hydrogen Content
}

\author{
I. Golovin, M. Kollerov, E. Schinaeva
}

\section{To cite this version:}

I. Golovin, M. Kollerov, E. Schinaeva. The Study of Microplasticity Mechanism in Ti-50 wt.\%Nb Alloy with High Hydrogen Content. Journal de Physique IV Proceedings, 1996, 06 (C8), pp.C8-289-C8-292. 10.1051/jp4:1996862 . jpa-00254670

\section{HAL Id: jpa-00254670 https://hal.science/jpa-00254670}

Submitted on 1 Jan 1996

HAL is a multi-disciplinary open access archive for the deposit and dissemination of scientific research documents, whether they are published or not. The documents may come from teaching and research institutions in France or abroad, or from public or private research centers.
L'archive ouverte pluridisciplinaire HAL, est destinée au dépôt et à la diffusion de documents scientifiques de niveau recherche, publiés ou non, émanant des établissements d'enseignement et de recherche français ou étrangers, des laboratoires publics ou privés. 


\title{
The Study of Microplasticity Mechanism in Ti-50 wt.\% Nb Alloy with High Hydrogen Content
}

\author{
I.S. Golovin, M.U. Kollerov and E.V. Schinaeva \\ Aviation Technology University, Petrovka 27, Moscow 103767, Russia
}

\begin{abstract}
The upper yield point $(\approx 700 \mathrm{MPa})$ appears at the compression test curves $\left(\varepsilon=0.024 \mathrm{sec}^{-1}\right)$ of b.c.c. $\mathrm{Nb}-50 \mathrm{wt} . \% \mathrm{Ti}$ due to the increase of hydrogen content from 0 to $0.2 \mathrm{wt} \%$ and more and leads to the non monotonous increase in compressive lower yield stress from 400 to $550 \mathrm{MPa}$. Taking into account close connection between macro- and microplasticity of metallic materials the low frequency $(\sim 2 \mathrm{~Hz})$ amplitude dependent internal friction (ADIF) spectrum $\left(\gamma=1.60 \cdot 10^{-5}\right)$ in hydrogenized $\mathrm{Nb}-50 \mathrm{wt} \% \mathrm{Ti}$ and $\mathrm{Nb}$ samples are studied. The ADIF investigation of the closed hysteresis loop "loading-unloading" shows the dependence of its width from the hydrogen content which evidences the fact of dislocation unpinning from hydrogen atmospheres in the $1 / 2$ cycle of loading. The study of ADIF spectrum for samples with different hydrogen content before and after torsion deformation $(\gamma \approx 2 \%)$ shows the sharp increase of IF level at $\gamma=1 . .10 \cdot 10^{-5}$ after $\approx 1$ hour of natural ageing. At that time the ADIF curves change its shape from $\Gamma$-shape to U-shape. The amplitude range of the IF increase depends on the hydrogen content. It is the interaction of hydrogen atoms with dislocations that caused the above mentioned effect which has not been observed in hydrogen free samples. The time estimation for the formation of thermodynamically stable hydrogen atmospheres on dislocations shows that hydrogen atmospheres could not follow the dislocation during compressive tests and that leads to the upper yield point appearance.
\end{abstract}

\section{INTRODUCTION}

The studied Ti-50wt.\% Nb alloy is a classical hard superconductor used for multichannel cables undergone to high degree plastic deformation. Hydrogen alloying influence deformation procedure [1]. The hydrogen solubility in solid solution depends on temperature as $C=5.35 \exp \left(-\Delta \mathbf{H}_{\mathrm{p}} / \mathrm{kT}\right)$ [1], where the enthalpy $\Delta H_{p}=0.12[\mathrm{eV} / \mathrm{H}]$. The interaction energy of hydrogen with edge dislocation was estimated to be about $-0.25 \mathrm{eV}$ and with screw dislocation - to be much less [2]. That leads to the considerable increase in hydrogen concentration in the vicinity of elastic distortions around non screw dislocations and especially in the dislocation cores. According to calculations performed in [3] the hydrogen concentration in dislocation cores is $>1000$ times higher than that in solid solution and reaches average concentration at the distance $20-30 \mathrm{~b}$ from dislocation line. From one hand it takes only about $0.3 \cdot 10^{-5} \mathrm{~s}$. to create the above mentioned hydrogen atmospheres at dislocations [4]. From the other hand the sharp yield point is observed on stress-strain compression test curves of hydrogenized $\mathrm{Nb}$-Ti, samples. The sharp yield point appearance is usually connected with dislocations breaking away from pinning points or atmospheres. So, the kinetics aspects of dislocations-hydrogen interaction is the subject of the present paper. Some details of hydrogen interaction in b.c.c. solid solution of $\mathrm{Nb}$ and $\mathrm{Nb}-\mathrm{Ti}$ alloy is discussed in [5].

\section{EXPERIMENTAL PROCEDURE}

The $\mathrm{Nb}-52 \mathrm{wt} . \% \mathrm{Ti}(\approx 0.1 \mathrm{wt} . \% \mathrm{O})$ and $\mathrm{Nb}(\approx 0.05 \mathrm{wt} . \% \mathrm{O})$ samples were vacuum melted and drawn into wires of $1 \mathrm{~mm}$ in diameter. The samples were annealed at $1073 \mathrm{~K}$ during 2 hours. Hydrogenizing was carried out at $800{ }^{\circ} \mathrm{C}$. The thermodiffusion hydrogenizing (up to $0.6 \mathrm{wt} . \%$ ) of alloy was done with the use of Sievert's equipment. After hydrogenizing the concentrations of hydrogen in $\mathrm{Nb}$ was 0.05 wt. $\%$ and in $\mathrm{Nb}$-Ti alloy that was $0.15 ; 0.22 ; 0.47 ; 0.86$ and $1.0 \mathrm{wt} . \% \mathrm{H}$. A few samples were deformed to $2 \%$ directly in torsion pendulum (except sample with $1 \mathrm{wt} \% \mathrm{H}$ which was broken after the deformation $\approx 1 \%$ ) in order to measure natural strain-ageing effect during $100 \mathrm{hrs}$. Amplitude dependent internal friction (ADIF) measurements were carried out with the use of free decay torsion inverted pendulum "RKM-TPI" $(\mathrm{f}=1-2 \mathrm{~Hz})$ in the amplitude range $\gamma=10^{-6}-10^{-3}$. All the ADIF measurements were performed without vacuum. Standard compression tests were carried out with the deformation rate $\varepsilon=0.024 \mathrm{sec}^{-1}$. 


\section{EXPERIMENTAL RESULTS and DISCUSSION}

The study of hydrogen influence on dislocation mobility is performed into three steps: the influence of hydrogen on the shape of ADIF curves; the influence of hydrogen on hysteresis loop during "loading-unloading" tests; the influence of hydrogen content on strain ageing effects.

The ADIF curve for hydrogen-free Nb-Ti samples has $\boldsymbol{\Gamma}$-type, i.e. the ADIF has two amplitude ranges where the IF dependence on amplitude of deformation was quite different: IF increases rapidly with the increase of amplitude of deformation at about $\gamma<20 \cdot 10^{-5}$ and then the slope of curve $\mathrm{Q}^{-1}$ vs. $\gamma$ becomes much more smaller but also nearly linear (Fig. 1). Similar ADIF curves were observed in Al-based alloys by Gelli [5] and in Be by Levin et. al. [6].

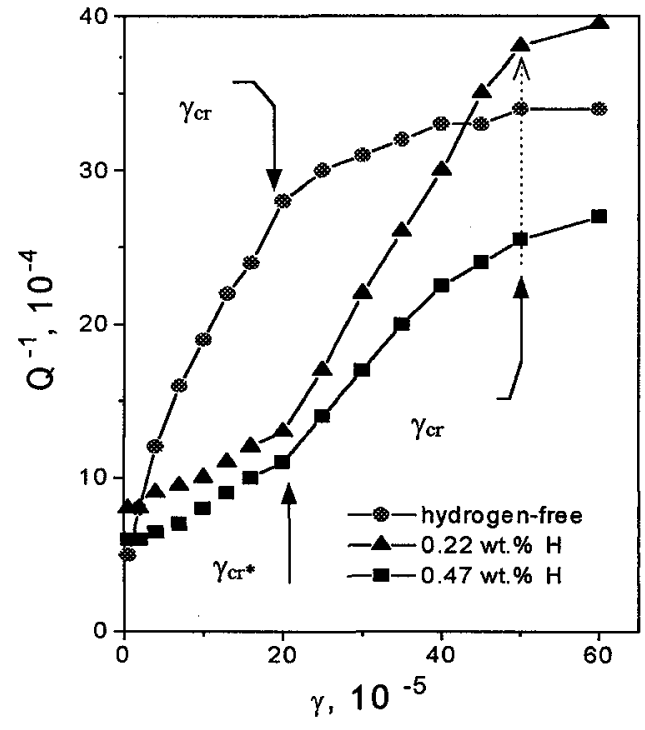

Fig. 1

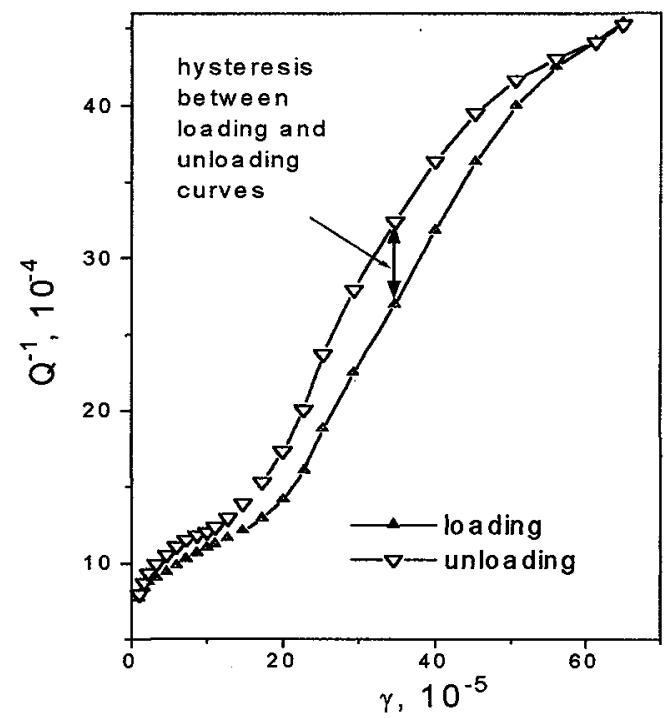

Fig. 2

Figure 1. The influence of hydrogenizing of $\mathrm{Nb}$-Ti alloy on the amplitude dependent IF curves shape.

Figure 2. ADIF loading and unloading curves at $\mathrm{f} \approx 2 \mathrm{~Hz}$ after averaging (3 points) and FTT filter (5 points) smoothing for $\mathrm{Nb}-\mathrm{Ti}$ alloy with $0.22 \mathrm{wt} . \% \mathrm{H}$.

Such a behaviour is the result of dislocation overcoming of pinning points in the range of relatively low stress: in $\mathrm{Al}$ it was subsitutional $\mathrm{Si}$ and $\mathrm{Co}$ atoms, in $\mathrm{Be}$ it was called [6] as "generalised friction force" of crystalline lattice, and "over barrier" motion in the range of higher stresses. The similar but quantitatively but much smaller effect (shape of ADIF curves) was observed in this work for $\mathrm{Nb}$.

The hydrogenizing leads to the shift of $\Gamma$-type curves to the higher amplitudes and to the appearance in the range of the lowest amplitude of deformations $\left(\gamma_{\mathrm{cr}^{*}}<20 \cdot 10^{-5}\right)$ a new range of ADIF curve with the relatively small slope $\mathrm{Q}^{-1}$ vs. $\gamma$ (Fig. 1). In the hydrogen free sample the critical amplitude of deformation is $\gamma_{\mathrm{cr}} \approx 20 \cdot 10^{-5}$ ) and corresponding critical stress is $\tau_{\mathrm{cr}} \approx 9 \mathrm{MPa}$. In hydrogenized samples corresponding these values are about $50 \cdot 10^{-5}$ and $20 \mathrm{MPa}$. Hydrogenizing pins the dislocations and only with the increase of applied stress the dislocation unpinning and corresponding increase of IF takes place. The similar effect in $\mathrm{Nb}$ is again worse pronounced, if any. So, the first conclusion is that in Nb-Ti alloy the hydrogenizing shifts the critical points at ADIF curves to higher amplitudes and makes the dislocation motion more difficult in the range of amplitudes of deformation investigated.

The second stage was to find out if the hydrogen atmospheres pin dislocations additionally to other types of pinning. In case it is so, the pinned by hydrogen dislocations are less moveable and 
give the smaller contribution to IF, but if some of them are hydrogen free they must lead to the increase in IF. The study of "loading" and "unloading" curves for hydrogen-free and hydrogenized samples gives such an opportunity. After the first loading cycle $\left(\gamma \approx 6 \cdot 10^{-4}\right)$ of oscillation $(t \approx 0.25 \mathrm{~s})$ which is 100000 times higher than the time necessary for dislocation pinning by hydrogen (according [3]) the dislocations loose their atmospheres and becomes more moveable. As a result, the unloading curves are situated higher than loading ones (Fig. 2). The comparison of IF for hydrogen-free and hydrogenized samples proves that the hydrogen pinning is rather considerable. So, the result is that dislocations can unpin from the hydrogen atmospheres. The last point is kinetics of dislocation-hydrogen interaction or, in the other words, for how long does it take the "fresh" hydrogen-free dislocations to be pinned at room temperature $\left(20{ }^{\circ} \mathrm{C}\right)$ by thermodynamically stable hydrogen atmospheres.

That question could be solved by studying the strain ageing influence on ADIF curves. Normally the plastic deformation of b.c.c. metals and alloys leads to the considerable increase in IF level due to the increase in structure imperfection and to the decrease in IF due to natural or artificial ageing. Such a behaviour is observed for $\mathrm{Nb}$. The situation is rather different for $\mathrm{Nb}-\mathrm{Ti}$ alloy: some increase in IF is observed for amplitude range $\gamma<20 \cdot 10^{-5}$, only, and to the decrease in IF at higher amplitudes. The IF level at the range $\gamma<20 \cdot 10^{-5}$ slowly decreases and IF level at the range $\gamma>20 \cdot 10^{-5}$ was practically permanent due to natural ageing.

The situation with hydrogenized samples was different and rather unexpected. Dependently from hydrogen content and ageing time the valuable increase in IF was observed on ADIF curves in the range of $\gamma<30 \cdot 10^{-5}$ (Fig. 3). Ageing changes the $\Gamma$-shape of ADIF curves to the $\mathbf{U}$-shape. This shape dominates after 1-20 hrs ageing and only then the left wing of ADIF curve completely disappears and again the $\Gamma$-shape of ADIF curve similar to that for non-deformed state is observed. The increase in hydrogen content shifts the effect of abnormal IF grows to higher amplitude within the above mentioned range of amplitude of deformations. As a matter of a fact such a behaviour evidences that the dislocation-hydrogen interaction at room temperature lasts for quite a long time before the equilibrium state of atmospheres is achieved. The increase in IF at low amplitude of deformation after a few hours of natural ageing is somehow connected with the formation due to diffusion and motion under the applied stress easy moveable hydrogen atmospheres at dislocations. The nature of those atmospheres is not clear enough and needs the further study.

On the macroscopic scale the long time formation of equilibrium hydrogen atmospheres at dislocations leads to the sharp yield point appearance, i. e. the "fresh" dislocations could not be pinned again during the active plastic deformation. At the compression test curves with the loading rate $\varepsilon=0.024 \mathrm{sec}^{-1}$ the upper yield point $(\approx 700 \mathrm{MPa})$ appears at for all the $\mathrm{Nb}$-Ti samples with hydrogen content $0.2 \mathrm{wt} . \%$ and higher (Fig. 4). The height of upper yield point depends slightly from the hydrogen content within $0.2-0.8 \mathrm{wt} . \%$. The increase of hydrogen content from 0 to 0.2 wt. \% slightly decreases and from 0.2 to $0.6 \mathrm{wt} . \%$ leads to the increase in compressive yield stress from 420 to $530 \mathrm{MPa}$. The influence of hydrogen on plastic deformation is discussed in [7]. 


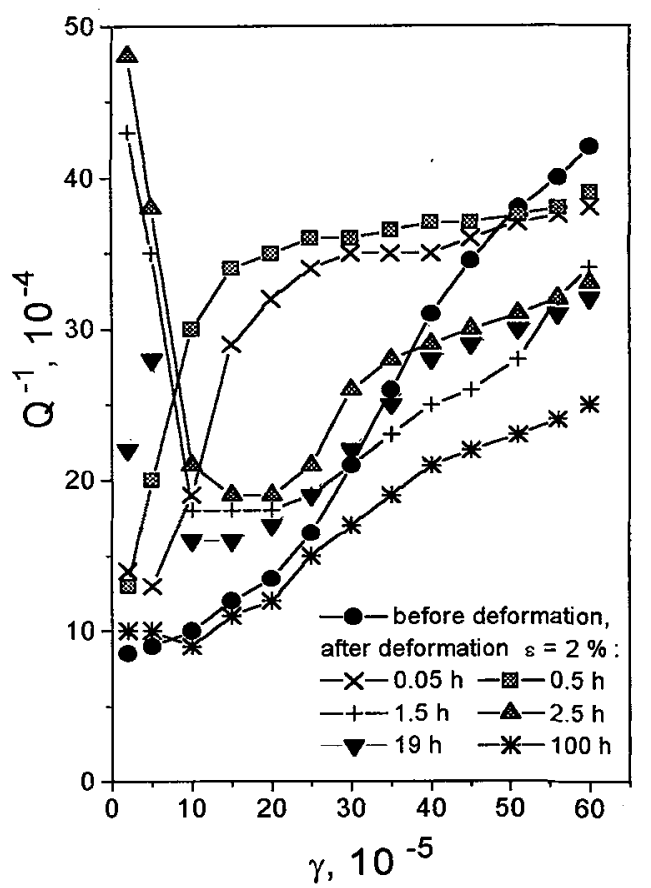

Fig. 3

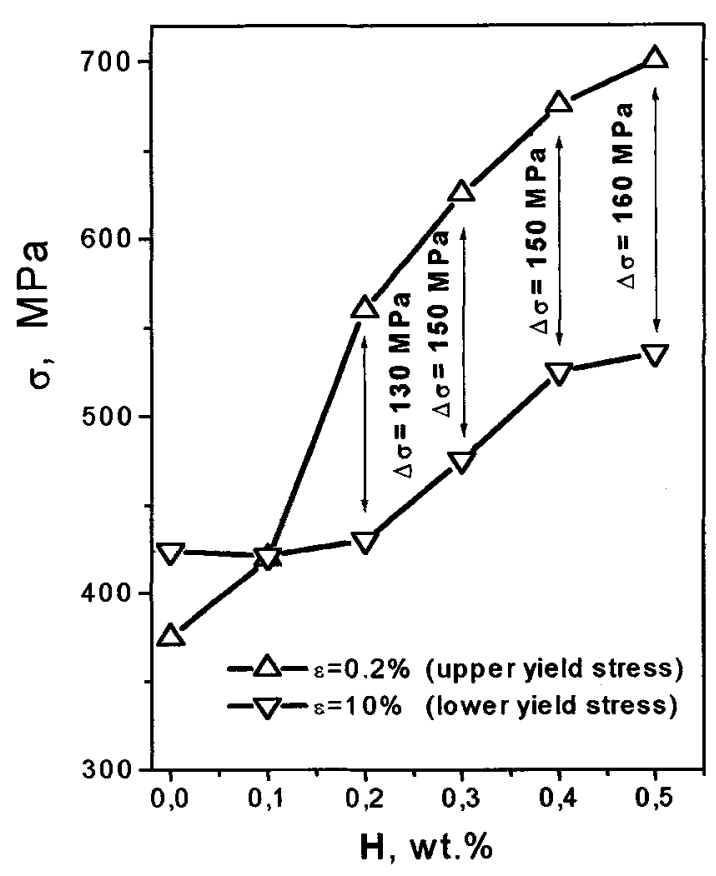

Fig. 4

Figure 3. The influence of strain-ageing time at room temperature on ADIF curves for $\mathrm{Nb}$-Ti alloy with $0.22 \mathrm{wt} \% \mathrm{H}$.

Figure 4. The influence of hydrogen content on upper and lower yield points at compressive tests with rate $\varepsilon=0.024 \mathrm{~s}^{-1}$.

\section{CONCLUSIONS}

The dislocations pinning by hydrogen atoms is confirmed using amplitude dependent internal friction study. Additional difference obtained in hydrogenised samples between "loading" and "unloading" ADIF curves proves the dislocation unpinning from hydrogen atmospheres. Time dependent internal friction effects during strain ageing evidences that at room temperature the hydrogen redistribution along dislocation takes considerably longer time than the estimations given in [3].

\section{References}

[1] Swalin R.A., Thermodynamics of Solids. Wiley and Sons, New York, 1972.

[2] Wert C. in Hydrogen in Metals II. Application-Oriented Properties. Edited by G.Alefeld and J.Volkl.Springer-Verlag.

Berlin, Heidelberg, New York, 1978.

[3] Kolachev B.A. Hydrogen brittleness of metals., Moscow, 1985

[4] Golovin I.S., Blanter M.S., Vasiliev A.V. The hydrogen influence upon oxygen Snoek relaxation in NbTi alloys. This conference.

[5] Gelli D. J. de Phisique, 1971, C.2, N 2, p.137-143

[6] Levin D.M., Lashuk N.K., Tkachenko V.G. et.al. Mechanism of dislocation anelasticity of polycrystalline Be. Kiev, 1989, Preprint AN YSSR, N 13, 36 p.

[7] Agarkova E.O., Schinaeva E.V., Kollerov M.U., Golovin I.S., International Symposium on Metal Hydrogen Systems. Aug.25-30, Les Diablerets, Switzerland. 